\title{
"Evaluation of Tooth Size Discrepancies among Different Malocclusion Groups In Sirte" -Libya
}

\author{
Dr. Rahamathulla Khan, Dr. Verdine Virginia Antony \\ ${ }^{1}$ ( Department of Orthodontics, Sirte University, Libya.) \\ 2 ( Department of Periodontics, Sirte University, Libya.)
}

\begin{abstract}
Background: Orthodontic diagnosis and treatment planning requires the patient's history, extra and intra oral examination, analysis of diagnostic records comprising of orthodontic photographs, radiographs and study casts. Tooth-size is the sum of the mesio distal widths of the maxillary and mandibular teeth. For ideal occlusion, teeth in both arches should be proportional in size. Tooth size analysis was presented by Bolton in 1958. The ratio for anterior segment was derived to be $77.2 \pm 0.22 \%$ and $91.3 \pm 0.26 \%$ for the whole arch.

Material And Methods: Cross sectional data was gathered from the study casts of patients undergoing orthodontic treatment. 115 out of 160 study casts were filtered based upon the inclusion and exclusion criteria. ANB angle and Witt's appraisal were traced on corresponding lateral cephalograms. The mesio distal widths of all maxillary and mandibular teeth from right first molar to left first molar were calibrated with the use of a manual caliper. The readings were then used to compute the anterior and total Bolton ratios.
\end{abstract}

Results: Significantly higher mean anterior tooth ratios were found for Class II $(p<0.01)$ patients. All other ratios were within close range of Bolton's norms.

Conclusions: Skeletal Class II patients showed a tendency towards higher mesiodistal widths of teeth in the mandibular anterior region.

Keywords: Bolton's norms, Interarch tooth size discrepancy, Skeletal Class I, II and III.

\section{Introduction}

A tooth size discrepancy (TSD) is a disproportion among the sizes of the individual teeth.[1] As significant tooth size discrepancies prevent an ideal occlusion being produced at the end of orthodontic treatment, the absence of a TSD is the seventh "key" for an ideal occlusion.[1 ]Overall, TSDs relate to all teeth excluding second permanent and third molars, whereas anterior TSDs involve the six anterior teeth. Among patients undergoing orthodontic treatment, the prevalence of an overall TSD has varied from 4\%-11\%[2,3]. Anterior TSDs, however, have a prevalence between $17 \%$ and $31 \%$ among orthodontic patients,[4] and this is similar to the prevalence of $20.5 \%$ in non-orthodontic patients.[4,5] The prevailance of TSDs are more common in cases of malocclusions namely, Class II division 1 malocclusions[6] and in Class III malocclusions[7] Studies have found larger tooth size ratios in men than in women, but the differences at $0.6 \%-1.0 \%$ were not significant. Smith et al.[8] found that Black people had the highest overall tooth size ratios (93.4\%) followed by Hispanics (92.3\%) and then Whites (91.2\%). The most common method of assessing a TSD involves the measurement of the mesiodistal widths of teeth using conventional fine-pointed calipers or digital calipers.

The purpose of this study was to evaluate the relationship between tooth size discrepancy and malocclusion groups based on cephalometric analysis, in orthodontic patients in Sirte, Libya.

\section{Materials And Methods}

A cross sectional study was carried out at Sirte Dental School and Hospital, after obtaining informed consent from the patients.

Inclusion Criteria:

- Permanent dentition

- Presence of all permanent teeth from first molar to first molar in both arches

- Subjects of Libyan ethnic group

- No caries or extensive restorations on any of the teeth

Exclusion Criteria:

- Presence of any deciduous tooth/teeth

- Presence of any morphologic dental anomaly namely mesiodens, taurodontism, etc.

- History of orthodontic treatment.

A thorough examination of all the study casts was done. All impressions of orthodontic patients were taken with fast setting alginate. Impressions were poured with orthodontic plaster, after which they were 
trimmed. 115 out of 160 study casts were filtered based upon the inclusion and exclusion criteria. ANB angle[9] and Witt's appraisa [10] were traced on corresponding lateral cephalograms on acetate sheet using $0.1 \mathrm{~mm}$ tracing pen to assess the skeletal class of the patients.The mesio distal widths of all maxillary and mandibular teeth from right first molar to left first molar were calibrated with the use of a manual calliper. The readings were then used to compute the anterior and total Bolton ratios.

All data was analyzed using SPSS-14. Mean and standard deviation were calculated for anterior and total Bolton ratios for the whole sample and also for all three skeletal groups individually. ANOVA was used to compare the three skeletal groups with each other and also with Bolton's proposed norms for total and anterior Bolton ratios. Tukey's test was used for post HOC analysis.

\section{Results:}

Out of a total of 160 casts studied, 115 were filtered based on the above mentioned criteria. Of these, 40 were of Class I patients, 60 were of Class II patients and 15 were of Class III patients based on the corresponding cephalometric evaluations. A mean total Bolton ratio of $91.22 \pm 2.83$ and a mean anterior Bolton ratio of 78.64 \pm 5.01 was found for the complete sample [ Table-1].

The minimum total Bolton ratio calculated in the sample was 83.91 of a skeletal Class II patient while the highest ratio calculated was 98.71 of a skeletal Class I patient. ANOVA and Tukey's test failed to show any significant difference in the total Bolton ratios of different sample groups $(p>0.05)$ [ Table-2].

The minimum anterior Bolton ratio calculated in the sample was 67.10 of a skeletal Class I patient while the highest ratio calculated was 98.00 of a skeletal Class II patient. ANOVA and Tukey's test showed significant difference for anterior Bolton ratios between Bolton's proposed norms and Class II patients and also between Class I and Class II patients. $(p<0.01)$ [ Table-3].

\section{Discussion:}

The clinician should be familiar with discrepancies in tooth size at the initial diagnosis and treatment planning stages if excellence in orthodontic finishing is to be achieved. Tooth size discrepancies are considered an important variable especially in the anterior segment.In our study, a comparison was made between tooth size discrepancy in skeletal Class I, II and III patients based on Cephalometric findings. The mean total ratio for the whole sample was $91.22 \%$ which is very close to Bolton's proposed ideal ratio. However the anterior ratio for the whole sample was found to be $78.64 \%$, which is higher than Bolton's proposed ideal ratio, thus reflecting a tendency towards greater mesiodistal widths in the mandibular anterior segment in our population sample.

In skeletal Class I patients, the mean total ratio calculated was $91.64 \%$ and the mean anterior ratio calculated was $77.56 \%$, both of which are close to Bolton's proposed ideal ratios. Similarly the total mean ratio calculated for skeletal Class II (90.59\%) and skeletal Class III (91.45\%) patients and the anterior mean ratio for skeletal Class III patients $(78.58 \%)$ was in close agreement with Bolton's proposed ideal ratios. A peculiarity was the finding of significantly higher $(p<0.05)$ mean anterior ratio $(81.21 \%)$ for class II patients. This reflects a tendency towards wider mesiodistal dimensions in the mandibular anterior segment in our study sample. There was a significant difference in the anterior tooth ratios between Class I and Class II patients. However, no significant difference between Class I and Class III or Class II and Class III patients was observed. No correlation between angle's classification of malocclusion and Bolton discrepancy was shown by Crossby and Alexander in 1989.[11]

Hashim in 2002[12] did not find any difference in Bolton's ratios between different malocclusion groups.

In 2005 Uysal et al[10] compared interarch tooth size discrepancy in 150 untreated, normal occlusion subjects and 560 patients of four different malocclusion groups. A gender dimorphism was found in the normal subjects. All malocclusion groups showed significantly higher overall ratios than normal occlusion groups $(\mathrm{p}<0.001)$. However no statistically significant difference was found between the malocclusion groups.

Al Khateeb and Abu Alhaija[13] in 2006 found no statistically significant differences in Bolton's ratios between the different malocclusions. Their sample consisted of 140 orthodontic models of school children aged between 13-15 years of Jordanian origin. The results of this study are in partial agreement with some of the above studies considering the fact that no significant difference was found between Bolton's norms and tooth size ratios in Class I patients. However, unlike other studies, Class III did not show a significantly higher anterior tooth ratio as compared to Class I patients. The observation that Class II subjects showed a significantly higher anterior ratio, indicating a tendency towards wider mandibular teeth. 
V. Tables:

Table 1:

Mean Tooth Size Ratios For Different Malocclusion Groups

\begin{tabular}{|l|l|l|}
\hline Group & $\begin{array}{l}\text { Mean total } \\
\text { ratio }\end{array}$ & $\begin{array}{l}\text { Mean anterior } \\
\text { ratio }\end{array}$ \\
\hline Complete sample [n=115] & 91.22 & 78.64 \\
& \pm 2.83 & \pm 5.01 \\
\hline Class I [n=40] & 91.64 & 77.56 \\
& \pm 3.25 & \pm 4.10 \\
\hline Class II [n=60] & 90.59 & 81.21 \\
& \pm 2.87 & \pm 5.31 \\
\hline Class III [n=15] & 91.45 & 78.58 \\
& \pm 2.31. & \pm 5.87 \\
\hline
\end{tabular}

Table 2:

ANOVA and Turkey's test for total Bolton's ratios

\begin{tabular}{|l|l|l|}
\hline Class & & $p$-Value \\
\hline & Total Bolton & 0.477 \\
\hline Class I & Boltons & 0.923 \\
& Class II & 0.410 \\
& Class III & 0.875 \\
\hline Class II & Boltons & 0.831 \\
& Class I & 0.412 \\
& Class III & 0.934 \\
\hline Class III & Boltons & 0.976 \\
& Class I & 0.862 \\
& Class II & 0.934 \\
\hline \multicolumn{2}{|r|}{$* p$-value $<0.05$ is significant }
\end{tabular}

Table 3:

ANOVA And Turkey's Test For Anterior Bolton's Ratios

\begin{tabular}{|l|l|l|}
\hline Class & & $p$-Value \\
\hline & Total ANOVA & $0.006^{*}$ \\
\hline Class I & Boltons & 0.968 \\
& Class II & $0.042^{*}$ \\
& Class III & 0.042 \\
\hline Class II & Boltons & 0.008 \\
& Class I & $0.042^{*}$ \\
& Class III & 0.936 \\
\hline Class III & Boltons & 0.188 \\
& Class I & 0.324 \\
& Class II & 0.925 \\
\hline
\end{tabular}

$* p$-value $<0.05$ is significant

\section{Conclusions:} population.

A larger study at the national level is required to verify the applicability of these results to the Libyan 


\section{References:}

[1]. Bolton WA. Disharmony in tooth size and its relation to the analysis and treatment of malocclusion. Angle Orthod. 1958; 28:113130.

[2]. Freeman JE, Maskeroni AJ, Lorton L. Frequency of Bolton tooth-size discrepancies among orthodontic patients. Am J Orthod Dentofacial Orthop. 1996;110:24-27.

[3]. Bernabe' E, Major PW, Flores-Mir C. Tooth-width ratio discrepancies in a sample of Peruvian adolescents. Am J Orthod Dentofacial Orthop. 2004; 125:361-365

[4]. Endo T, Abe R, Kuroki H, Oka K, Shimooka S. Tooth size discrepancies among different malocclusions in a Japanese orthodontic population. Angle Orthod. 2007;78:994-999.

[5]. Strujic M, Anic-Milosevic S, Mestrovic S, Slaj M. Tooth size discrepancy in orthodontic patients among different malocclusion groups. Eur J Orthod. 2009;31:584-589.

[6]. Othman SA, Harradine NW. Tooth size discrepancies in an orthodontic population. Angle Orthod. 2007;77:668-67

[7]. Araujo E, Souki M. Bolton anterior tooth size discrepancies among different malocclusion groups. Angle Orthod. 2003; 73:307-313.

[8]. Smith SS, Buschang PH, Watanabe E. Interarch tooth size relationships of 3 populations: “does Bolton's analysis apply?' Am J Orthod Dentofacial Orthop. 2000;117:169-174.

[9]. Alkofide E, Hashim H. Intermaxillary tooth size discrepancies among different malocclusion classes: a comparative study. J Clin Pediatr Dent. 2002;26:383-387.

[10]. Uysal T, Sari Z. Intermaxillary tooth size discrepancy and mesiodistal crown dimensions for a Turkish population.Am J Orthod Dentofacial Orthop. 2005;128:226-230.

[11]. Crosby DR, Alexander CG. The occurrence of tooth size discrepancies among different malocclusion groups. Am J Orthod Dentofacial Orthop. 1989;95:457-461.

[12]. Hashim HA. Bolton tooth size ratio among different malocclusion groups: A pilot study. J Pak Dent Assoc 2002;11:81-5.

[13]. Al-Khateeb SN, Abu-Alhaija ESJ. Tooth size discrepancies and arch parameters among different malocclusions in a Jordanian sample. Angle Orthod 2006;76:459-65. 